\title{
Preparation of Cationic Amphiphilic Nanoparticles with Modified Chitosan Derivatives for Doxorubicin Delivery
}

\author{
Xiudong Liu ${ }^{1, *}$, Huofei Zhou ${ }^{2}$, Weiting Yu ${ }^{3, *}$, Xin Xiong ${ }^{4}$, Rumen Krastev ${ }^{4,5}$ and Xiaojun Ma ${ }^{2}$ \\ 1 College of Environment and Chemical Engineering, Dalian University, Dalian 116622, China \\ 2 Laboratory of Biomedical Material Engineering, Dalian Institute of Chemical Physics, \\ Chinese Academy of Sciences, Dalian 116023, China; hfzhou@dicp.ac.cn (H.Z.); maxj@dicp.ac.cn (X.M.) \\ 3 The Affiliated Zhongshan Hospital, Dalian University, Dalian 116001, China \\ 4 NMI Natural and Medical Sciences Institute, University of Tübingen, 72770 Reutlingen, Germany; \\ xin.xiong@nmi.de (X.X.); rumen.krastev@reutlingen-university.de (R.K.) \\ 5 School of Applied Chemistry, Reutlingen University, 72762 Reutlingen, Germany \\ * Correspondence: liuxiudong@dlu.edu.cn (X.L.); yuwt@dicp.ac.cn (W.Y.)
}

Citation: Liu, X.; Zhou, H.; Yu, W.; Xiong, X.; Krastev, R.; Ma, X.

Preparation of Cationic Amphiphilic Nanoparticles with Modified Chitosan Derivatives for Doxorubicin Delivery. Materials 2021, 14, 7010. https://doi.org/10.3390/ma14227010

Academic Editors: Mutlu Özcan and Alina Sionkowska

Received: 29 June 2021

Accepted: 9 November 2021

Published: 19 November 2021

Publisher's Note: MDPI stays neutral with regard to jurisdictional claims in published maps and institutional affiliations.

Copyright: () 2021 by the authors. Licensee MDPI, Basel, Switzerland. This article is an open access article distributed under the terms and conditions of the Creative Commons Attribution (CC BY) license (https:// creativecommons.org/licenses/by/ $4.0 /)$.

\begin{abstract}
Polymeric micelle-like nanoparticles have demonstrated effectiveness for the delivery of some poorly soluble or hydrophobic anticancer drugs. In this study, a hydrophobic moiety, deoxycholic acid (DCA) was first bonded on a polysaccharide, chitosan (CS), for the preparation of amphiphilic chitosan (CS-DCA), which was further modified with a cationic glycidyltrimethylammounium chloride (GTMAC) to form a novel soluble chitosan derivative (HT-CS-DCA). The cationic amphiphilic HT-CS-DCA was easily self-assembled to micelle-like nanoparticles about $200 \mathrm{~nm}$ with narrow size distribution (PDI 0.08-0.18). The zeta potential of nanoparticles was in the range of 14 to $24 \mathrm{mV}$, indicating higher positive charges. Then, doxorubicin (DOX), an anticancer drug with poor solubility, was entrapped into HT-CS-DCA nanoparticles. The DOX release test was performed in PBS (pH 7.4) at $37^{\circ} \mathrm{C}$, and the results showed that there was no significant burst release in the first two hours, and the cumulative release increased steadily and slowly in the following hours. HT-CS-DCA nanoparticles loaded with DOX could easily enter into MCF-7 cells, as observed by a confocal microscope. As a result, DOX-loaded HT-CS-DCA nanoparticles demonstrated a significant inhibition activity on MCF-7 growth without obvious cellular toxicity in comparison with blank nanoparticles. Therefore, the anticancer efficacy of these cationic HT-CS-DCA nanoparticles showed great promise for the delivery of DOX in cancer therapy.
\end{abstract}

Keywords: cationic amphiphilic chitosan; self-assembled nanoparticles; doxorubicin; drug delivery

\section{Introduction}

Most anticancer drugs are poorly soluble, which gives rise to considerable challenges for their clinical application. To promote the solubility of drugs, some surfactants such as Cremophor EL/ethanol, and Tween 80 are usually used. These reagents, however, can cause several side effects on the liver and kidneys, and cause dose-dependent hemolysis and acute hypersensitivity reactions [1]. Therefore, numerous nanocarriers for the delivery of poorly soluble or hydrophobic drugs have been developed, such as polymeric nanoparticles, liposomes, hydrogels, and mesoporous silica nanoparticles. Many of them have been engineered for improving drug solubility and stability in serum, enhancing bioavailability in vivo and reducing drug toxicity and side effects in recent decades [2-5]. Polymeric micelle-like nanoparticles self-assembled from biodegradable and biocompatible amphiphilic block copolymers and hydrophobically modified water-soluble polymers have been extensively investigated for drug delivery application [6-8]. The cationic polymeric nanoparticles usually display good water solubility and high cellular uptake efficiency [9]. Moreover, cationic polymeric nanoparticles are usually made up of hydrophobic core and hydrophilic cationic shell based on self-assembly. The hydrophobic core can serve as a drug 
reservoir for most hydrophobic anticancer drugs, and the cationic shell can interact with DNA, siRNA, protein, or peptide to accomplish simultaneously co-delivery of different kinds of drugs on chemotherapy with synergistic effects [10-13].

Chitosan (CS), the only natural cationic polysaccharide, has been widely used for the delivery of both anticancer drugs and biochemical drugs [14-22] in the above-mentioned forms. In our previous study, CS was modified with a hydrophobic molecule of deoxycholic acid and hydrophilic glycidyl to obtain soluble amphiphilic chitosan derivative (G-CSDCA), which showed effective delivery of doxorubicin (DOX) and anticancer activity in MCF-7 cells [18]. However, the zeta potential values were as small as $0-2 \mathrm{mV}$, which was considered insufficient for the improvement of cell absorption of nanoparticles. In this study, CS was first modified with a hydrophobic molecule of deoxycholic acid (DCA) for the preparation of amphiphilic chitosan (CS-DCA). Then, a cationic hydrophilic molecule glycidyltrimethylammounium chloride (GTMAC) was grafted on CS to produce a novel cationic amphiphilic chitosan derivative, $\mathrm{N}$-(2-hydroxy)propyl-3-trimethylammonium CSDCA (HT-CS-DCA), with the purpose to improve both the solubility and the positive charge density. The grafting of hydrophobic and hydrophilic moieties on CS forming HT-CS-DCA was demonstrated by Fourier transform infrared (FTIR) spectroscopy and ${ }^{1} \mathrm{H}$ NMR. The elemental analysis was used to calculate the degree of substitution. The fluorescence probe, pyrene, was used to prove the formation of micelle-like HT-CS-DCA nanoparticles. The morphology, size, and zeta potential of nanoparticles were tested. Then, doxorubicin (DOX) was loaded into HT-CS-DCA nanoparticles, and the DOX release profile was studied. The growth inhibition against MCF-7 cells of HT-CS-DCA nanoparticles and antitumor efficacy of DOX-loaded HT-CS-DCA nanoparticles was evaluated through methyl tetrazolium (MTT) assay and confocal microscopy, which confirmed the low toxicity of carrier but a high cellular uptake and significant antitumor activity of DOX-loaded HTCS-DCA nanoparticles.

\section{Materials and Methods}

\subsection{Materials}

The raw chitosan was bought from Yuhuan Ocean Biochemical Co., Ltd. (Zhejiang, China) with $\mathrm{M}_{\mathrm{w}}=230 \mathrm{kDa}$, degree of deacetylation, $\mathrm{DD}=97 \%$. Both 1-ethyl-3-(3-dimethylaminopropyl) carbodiimide hydrochloride (EDC $\bullet \mathrm{HCl}), \mathrm{N}$-hydroxysuccimide (NHS), and fluorescent pyrene were bought from Acros Organics (Geel, Belgium). Deoxycholic acid (DCA), and glycidyltrimethylammounium chloride (GTMAC) were obtained from Sigma Co. (Cream Ridge, NJ, USA). Doxorubicin $\bullet \mathrm{HCl}(\mathrm{DOX} \bullet \mathrm{HCl})$ was a gift from Hisun Pharmaceutical Co. Ltd., (Zhejiang, China). All other chemicals and materials were obtained from Damao chemical reagent Co., (Tianjing, China) and applied as received.

\subsection{Preparation of Cationic Amphiphilic Chitosan HT-CS-DCA}

A total of $24 \mathrm{kDa} C S$ was obtained with the degradation from raw CS using $\mathrm{NaNO}_{2}$ [23]. The introduction of hydrophobic molecule DCA with the help of EDC and NHS resulted in amphiphilic chitosan derivative CS-DCA. Briefly, DCA (at a feed ratio of $10 \%$ to $30 \%$ of deoxycholic acid to glucosamine units), activators EDC and NHS (EDC/DCA $=1.2 / 1$ ) were dissolved in $100 \mathrm{~mL}$ of DMSO and pre-reacted for $30 \mathrm{~min}$; both DCA and EDC/NHS were mixed for activation. Subsequently, the activated DCA solution was dropped into CS solution (4 g $24 \mathrm{kDa}$ CS dissolved in $200 \mathrm{~mL}$ acidic solution (pH 5.6)) in $60 \mathrm{~min}$. After reaction for $24 \mathrm{~h}$, the solution was added into methanol/ $\mathrm{NaOH}$ solution $(300 \mathrm{~mL}, \mathrm{pH}$ ) With the centrifugation, the sediment was obtained, washed with a mixture of alcohol and water, respectively, and then vacuum dried. CS-DCA samples with different degrees of substitute (DS) of DCA were obtained by changing the amounts of DCA.

Secondly, a cationic hydrophilic molecule glycidyltrimethylammounium chloride (GTMAC) was grafted on HCS-DCA to produce a novel cationic amphiphilic chitosan derivative (HT-CS-DCA), with the purpose to improve both the solubility and the positive charge density. CS-DCA $(1.0 \mathrm{~g})$ was dispersed in $50 \mathrm{~mL}$ acetic acid solution for at least $6 \mathrm{~h}$. 
Then, GTMAC was added dropwise at the mole ratio of 3:1-5:1 (GTMAC to glucosamine units in CS-DCA) to produce HT-CS-DCA with different DS of GTMAC. After reaction for $24 \mathrm{~h}$ at $1000 \mathrm{rpm}$ at $50{ }^{\circ} \mathrm{C}, \mathrm{NaOH}$ was used to change the solution $\mathrm{pH}$ to 8 . The mixture was separated from undissolved polymer with centrifugation ( $8000 \mathrm{rpm}, 30 \mathrm{~min})$. Finally, the solution was dialyzed against deionized water for more than 3 days, with repeated changes of water and lyophilized for further experiments.

\subsection{Preparation HT-CS-DCA and DOX-Loaded HT-CS-DCA Nanoparticles}

A total of $10 \mathrm{~mL}$ of PBS (0.02 M, pH 7.4) was used to dissolve HT-CS-DCA (20 mg). The solution was placed into a probe sonicator (JY92-II, Ningbo, Zhejiang, China) and sonicated at $60 \mathrm{~W}$ for 2 min with a pulse off for $1 \mathrm{~s}$ and an interval of $5 \mathrm{~s}$. Then, the membrane filter (pore size: $0.45 \mu \mathrm{m}$, Millipore) was used to remove possible impurities or too large particles. The obtained HT-CS-DCA nanoparticles solution was stored for further test.

DOX was encapsulated in HT-CS-DCA nanoparticles by dialysis. For this procedure, $4 \mathrm{~mL}$ water/DMSO $(v / v=1 / 9)$ mixture was used as a solvent for HT-CS-DCA (20 mg), while DOX was neutralized by a 3 molar excess of triethylamine in $1 \mathrm{~mL}$ of DMSO. After mixing DOX and HT-CS-DCA solutions, the mixture was stirred for one hour and then dialyzed against PBS (0.01 M, pH 7.4) using a dialysis membrane ( $\mathrm{MWCO}=3500 \mathrm{Da})$ for $24 \mathrm{~h}$ at room temperature. Finally, the dialyzed solution was filtered through a $0.8 \mu \mathrm{m}$ membrane and freeze dried. All procedures were performed in the dark.

\subsection{Measurements}

\subsubsection{Characterization of Chitosan Derivatives}

The synthesized CS-DCA and HT-CS-DCA were firstly dried and characterized with a Bruker spectrometer (VECTOR22, Fällanden, Switzerland). The operating condition was from 4000 to $400 \mathrm{~cm}^{-1}$ with a resolution of $4 \mathrm{~cm}^{-1}$.

Using a Bruker Avance $500 \mathrm{MHz}$ spectrometer (Fällanden, Switzerland), the above samples were tested to give ${ }^{1} \mathrm{H}$ NMR spectra in deuterated water $\left(\mathrm{D}_{2} \mathrm{O}\right)$ at room temperature.

The DS of DCA or GTMAC was referred to as the percentage of DCA or GTMAC in 100 chitosan residues. The $\mathrm{C}, \mathrm{H}$, and, $\mathrm{N}$ amounts of each sample were determined by elemental analysis (Elemental Analyzer Vario EL, III, Hanau, Germany). Thereafter, the DS of DCA or GTMAC of the synthesized CS samples was calculated according to the $\mathrm{C}, \mathrm{H}$, and $\mathrm{N}$ ratios in $\mathrm{CS}$ and its derivatives. The derivatives were designated as $\mathrm{HT}_{\text {(DS of GTMAC) }}{ }^{-\mathrm{CS}-\mathrm{DC} \mathrm{A}_{(\mathrm{DS}} \text { of DCA) }}$.

\subsubsection{Critical Aggregation Concentration (CAC)}

To determine the critical aggregation concentration (CAC) of HT-CS-DCA samples in PBS buffer (0.02 M, pH 7.4), pyrene was used as a fluorescence probe. In volumetric flasks, $5 \mathrm{~mL}$ HT-CS-DCA solution with different concentrations was mixed with pyrene (final concentration of $6.0 \times 10^{-7} \mathrm{M}$ ). A luminescence spectrometer (LS55, PerkinElmer, Waltham, MA, USA) was used to give fluorescence spectra at room temperature. The emission spectra were collected at a scan speed of $120 \mathrm{~nm} / \mathrm{min}$ within the wavelength range of 350 to $450 \mathrm{~nm}$ and the excitation wavelength was $336 \mathrm{~nm}$. The first band ( $373 \mathrm{~nm}$, $\left.\mathrm{I}_{1}\right)$ and the third band $\left(383 \mathrm{~nm}, \mathrm{I}_{3}\right)$ in the emission spectra were obtained, then the intensity ratio $\left(\mathrm{I}_{1} / \mathrm{I}_{3}\right)$ was calculated with the change of polymer concentrations. Furthermore, the first turning point in the curve of $\mathrm{I}_{1} / \mathrm{I}_{3}$ ratio-polymer concentration was considered as the CAC.

\subsubsection{Morphology, Size, and Zeta Potential}

The morphology of HT-CS-DCA nanoparticles was observed by TEM (JEM-2000 EX, Joel Ltd., Tokyo, Japan), operating at an acceleration voltage of $120 \mathrm{kV}$.

A Malvern analyzer for nanoparticles (Zetasizer Nano ZS90, Malvern, UK) was applied to determine the nanoparticle size. At least three independent measurements for each 
nanoparticle $(2 \mathrm{mg} / \mathrm{mL})$ were carried out, and the results regarding size and zeta potential were displayed as the average value \pm standard deviation.

\subsubsection{Drug Loading}

The loading amount of DOX in HT-CS-DCA nanoparticles was analyzed by UV-Vis spectrophotometer (Shimadzu Co., Kyoto, Japan) with the predetermined calibration curve (a serial dilution of DOX in PBS solutions at $481 \mathrm{~nm}$ ). The drug loading content (LC) of DOX was calculated according to Equation (1).

$$
L C(w t \%)=\frac{\text { drug amount in nanoparticles }}{\text { amount of nanoparticles }} \times 100 \%
$$

\subsection{Release of DOX from HT-CS-DCA Nanoparticles In Vitro}

DOX-loaded HT-CS-DCA nanoparticles were put into PBS (0.02 M, pH7.4), and the release behavior was studied in vitro. Briefly, DOX-HT-CS-DCA nanoparticles ( $3 \mathrm{mg}$ ) were dispersed in $3 \mathrm{~mL}$ PBS ( $\mathrm{pH} 7.4$ ), then the suspension was transferred to a dialysis membrane $(\mathrm{MWCO}=3500 \mathrm{Da})$. The release was achieved in the dialysis membrane by gentle agitation $(100 \mathrm{rpm})$ in $30 \mathrm{~mL}$ PBS at $37^{\circ} \mathrm{C}$. A total of $3 \mathrm{~mL}$ of samples was extracted from the outer solution at fixed times, and $3 \mathrm{~mL}$ fresh buffer was added. According to the standard curve, DOX concentrations could be determined.

\subsection{Confocal Laser Scanning Microscopic (CLSM) Observations on Cellular Uptake}

Cellular uptake by MCF-7 human breast cancer cells and intracellular release of DOX from HT-CS-DCA nanoparticles were examined using CLSM (Leica, Germany). MCF-7 cells were introduced onto plates with an initial cell density of $2 \times 10^{4}$ cells/well, cultivated with media containing 10\% FBS for $24 \mathrm{~h}$. Then, the DOX-HT $\mathrm{H}_{42}-\mathrm{CS}-\mathrm{DCA}_{3.2}$ nanoparticles or free DOX were dissolved in culture media at a concentration of $5 \mu \mathrm{g} / \mathrm{mL}$. The cells were exposed to the media with either DOX-HT $42-\mathrm{CS}-\mathrm{DCA}_{3.2}$ nanoparticles or DOX $\bullet \mathrm{HCl}$ for 2 and $5 \mathrm{~h}$, respectively, at $37{ }^{\circ} \mathrm{C}$ in a humidified environment with $5 \% \mathrm{CO}_{2}$. After removing the culture media, the MCF-7 cells were washed with PBS three times prior to the CLSM-imaging with excitation wavelength $485 \mathrm{~nm}$ and emission wavelength $595 \mathrm{~nm}$.

\subsection{Cellular Viability Study In Vitro}

MCF-7 cells were seeded in the 96-well plate (10,000 cells/well), and cultured overnight, with $200 \mu \mathrm{L}$ of RPMI 1640 (10\% FBS) in a humidified environment at $37{ }^{\circ} \mathrm{C}$ with $5 \% \mathrm{CO}_{2}$ to assess the cytotoxicity of $\mathrm{CS}$ derivatives and DOX-loaded nanoparticles. Meanwhile, samples of different drug formulations were added in PBS buffer ( $\mathrm{pH} 7.4)$, followed by serial dilution to obtain a range of final drug concentrations. At a suitable time, a total $200 \mu \mathrm{L}$ mixture $(20 \mu \mathrm{L}$ of nanoparticle solution and $180 \mu \mathrm{L}$ of fresh medium) was used to replace the old culture medium in plates to keep the DOX concentration within a certain range. Finally, the cytotoxicity of CS derivatives was also determined in the culture medium $(0-1000 \mu \mathrm{g} / \mathrm{mL})$. The cells were cultured under the same condition as described above for $48 \mathrm{~h}$. Thereafter, aliquots of assay solution containing $180 \mu \mathrm{L}$ fresh medium and $20 \mu \mathrm{L}$ MTT solutions $(5 \mathrm{mg} / \mathrm{mL})$ were applied to replace the mixture in each well. After $4 \mathrm{~h}$ of incubation, the assay solution was removed and $200 \mu \mathrm{L}$ DMSO was added to each well. Then, the absorbance of the dissolved formazan crystals was measured by a microplate reader (Well Scan MK3, Labsystems Dragon, Finland) at 50 nm, and the reference wavelength was $630 \mathrm{~nm}$. The absolute absorbance of each well was then calculated by subtraction of -absorbance $630 \mathrm{~nm}$ from the- absorbance $_{550 \mathrm{~nm}}$. Then, the relative cell viability can be calculated using Equation (2).

$$
\text { cell viability }(\%)=\frac{\mathrm{OD}_{\text {sample }}}{\mathrm{OD}_{\text {control }}} \times 100 \%
$$


where $\mathrm{OD}_{\text {control }}$ was determined without polymers, and $\mathrm{OD}_{\text {sample }}$ was determined with polymers. The data were displayed as average value \pm SD for six parallel samples.

\section{Results and Discussion}

\subsection{Preparation of Cationic Amphiphilic Chitosan Derivatives HT-CS-DCA}

Scheme 1 displayed the route of synthesizing cationic amphiphilic chitosan derivatives HT-CS-DCA.

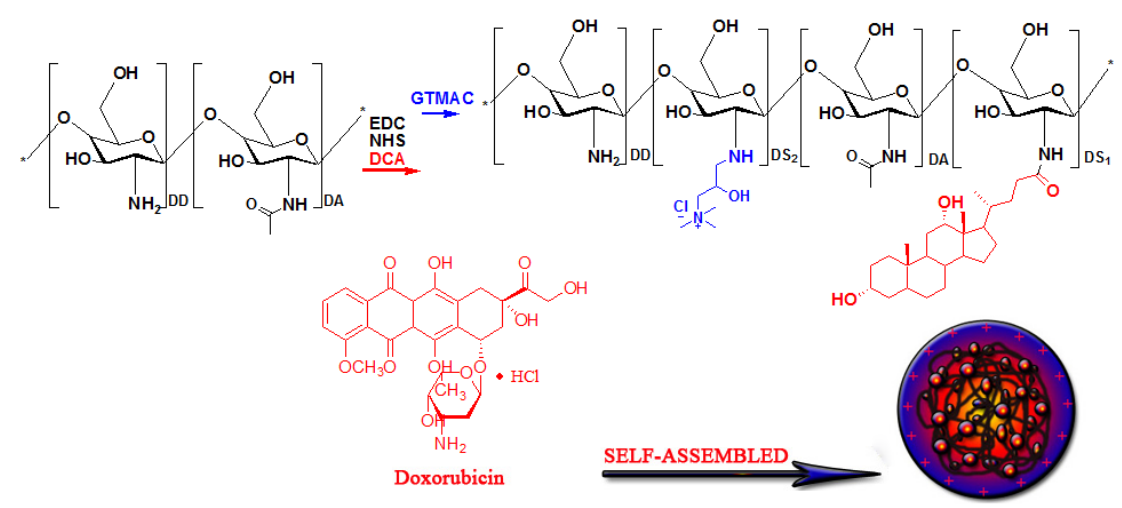

Scheme 1. The synthesis route of HT-CS-DCA and schematic of encapsulation of DOX based on self-assembly.

With EDC and NHS, hydrophobic DCA was first grafted onto chitosan-producing amphiphilic derivative CS-DCA. In FTIR analyses, a clearly enhanced peak at $1652 \mathrm{~cm}^{-1}$ (amide I band) in CS-DCA 3.2 (DS of DCA is 3.2) can be seen compared with the CS spectrum. The peak at $1600 \mathrm{~cm}^{-1}\left(-\mathrm{NH}_{2}\right)$ demonstrated a weakened $\mathrm{N}-\mathrm{H}$ bending vibration (Figure 1). It was found that the amide I band $\left(1652 \mathrm{~cm}^{-1}\right)$ sharpened as the feed ratio of DCA to chitosan increased [17]. By elemental analysis, the DS of DCA can be calculated as above-mentioned.

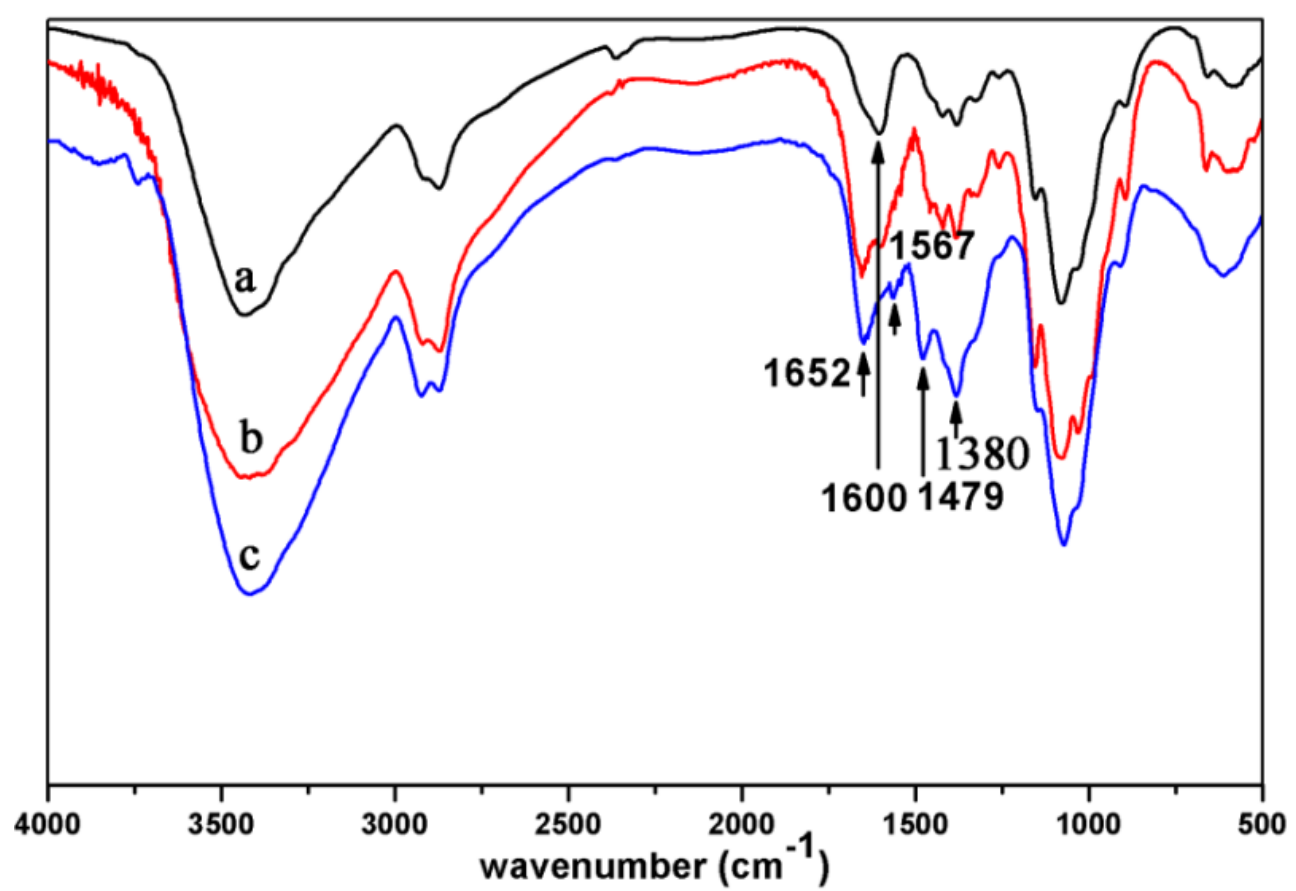

Figure 1. The FTIR spectra of (a) CS (DD = 97\%); (b) CS-DCA $3.2 ;$ (c) $\mathrm{HT}_{42}-\mathrm{CS}-\mathrm{DCA}_{3.2} ; 42$ and 3.2 refer to the DS of GTMAC and DCA, respectively. 
Secondly, GTMAC was grafted on CS-DCA to obtain HT-CS-DCA following the synthesis route in Scheme 1. The FTIR spectra of CS, CS-DCA ${ }_{3.2}$, and $\mathrm{HT}_{42}-\mathrm{CS}_{-}-\mathrm{DCA}_{3.2}$ (DS of GTMAC is 42) are shown in Figure 1. By comparing the FTIR spectra of CS-DCA 3.2 and $\mathrm{HT}_{42}$-CS-DCA 3.2 , the peak $1600 \mathrm{~cm}^{-1}\left(-\mathrm{NH}_{2}\right)$ further weakened, and the peak $1567 \mathrm{~cm}^{-1}$ was attributed to the vibration of amide II of GTMAC. Meanwhile, the increase in peaks at $1479 \mathrm{~cm}^{-1}$ (C-H deformations) and $1380 \mathrm{~cm}^{-1}\left(-\mathrm{CH}_{3}\right.$ symmetrical deformation) also meant the successful grating of GTMAC on CS-DCA.

Figure 2 shows the ${ }^{1} \mathrm{H}$ NMR spectra of $\mathrm{HT}-\mathrm{CS}$ and $\mathrm{HT}_{42}-\mathrm{CS}-\mathrm{DCA}_{4.2}$. The peak at $3.2 \mathrm{ppm}$ represented $-{ }^{+} \mathrm{N}\left(\mathrm{CH}_{3}\right)_{3}$ in GTMAC, and the peaks at $2.9 \mathrm{ppm}$ and $2.5 \mathrm{ppm}$ showed the $-\mathrm{NH}-\mathrm{CH}_{2}-$ group in GTMAC. The peaks at 2.67-2.76 ppm belonged to $\mathrm{C}-2$ in the saccharide unit for both HT-CS and HT-CS-DCA. Based on the comparison of ${ }^{1} \mathrm{HNMR}$ spectra of Figure 2a,b, it might be that the hydrophobic molecule DCA was introduced into CS resulting in new peaks between 0.7 and $1.9 \mathrm{ppm}$.

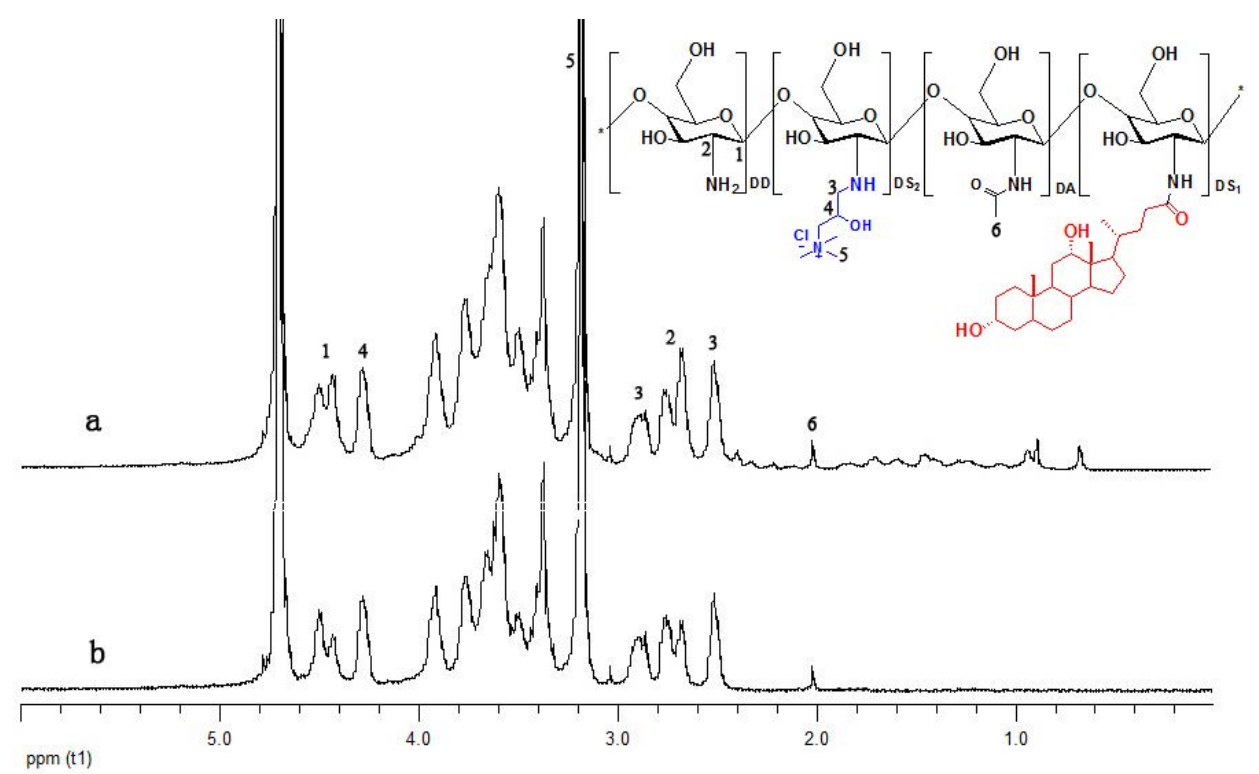

Figure 2. Spectra of chitosan derivatives analyzed by ${ }^{1} \mathrm{H}$ NMR: (a) $\mathrm{HT}_{42}-\mathrm{CS}-\mathrm{DCA}_{4.2}$; (b) HT-CS.

\subsection{Morphology, CAC, Size, and Zeta Potential of HT-CS-DCA Nanoparticles}

TEM characterization demonstrated that the HT-CS-DCA nanoparticles have spherical shapes (Figure 3a). Together with the dynamic light scattering detection (Figure 3b), HT-CSDCA nanoparticles were displayed relatively uniform in size. Moreover, the nanoparticles maintained higher size stability when stored at room temperature for more than 4 months (Figure 3c).
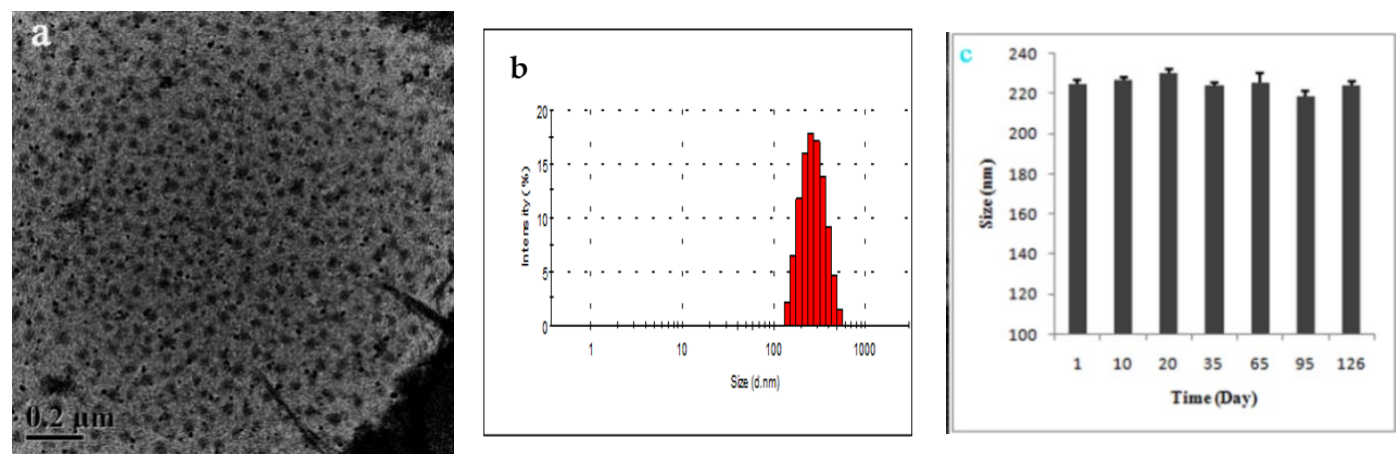

Figure 3. TEM images (a), size distribution (b), and size stability with time (c) of cationic amphiphilic $\mathrm{HT}_{42}-\mathrm{CS}^{-\mathrm{DCA}_{3.2}}$ nanoparticles in PBS $(2 \mathrm{mg} / \mathrm{mL})$ at room temperature. 
On the one hand, the CAC value is considered as an index to demonstrate the formation of micelle-like nanoparticles by self-assembly; on the other hand, it is an indication for nanoparticle stability in the circulatory system after the drug administration. As a molecular fluorescence probe, pyrene is useful to test the CAC of amphiphilic polymers. The effect of different DS values of DCA and GTMAC on the CAC of HT-CS-DCA is displayed in Table 1. With the DS increase in hydrophobic DCA and the DS decrease in hydrophilic GTMAC, CAC values of HT-CS-DCA reduced. Moreover, CAC values ranging from 0.023 to $0.079 \mathrm{mg} / \mathrm{mL}$ depended on DS of DCA (2.3 to 4.2) and GTMAC (42 to 84). It suggested that stable HT-CS-DCA nanoparticles were formed at low concentrations.

Table 1. CAC, size, and zeta potential of HT-CS-DCA nanoparticles.

\begin{tabular}{|c|c|c|c|}
\hline Sample ${ }^{a}$ & CAC (mg/mL) & Size $(\mathrm{nm})^{b}$ & Zeta Potential $(\mathrm{mV})$ \\
\hline $\mathrm{HT}_{42}-\mathrm{CS}-\mathrm{DCA}_{2.3}$ & 0.079 & $185.8 \pm 3.4(0.18)$ & $14.1 \pm 0.6$ \\
\hline $\mathrm{HT}_{42}$-CS-DCA 3.2 & 0.035 & $224.0 \pm 2.6(0.09)$ & $14.6 \pm 0.4$ \\
\hline $\mathrm{HT}_{42}-\mathrm{CS}-\mathrm{DCA}_{4.2}$ & 0.023 & $233.6 \pm 3.0(0.08)$ & $15.7 \pm 0.8$ \\
\hline $\mathrm{HT}_{61}$-CS-DCA 3.2 & 0.045 & $229.0 \pm 1.7(0.07)$ & $17.1 \pm 1.0$ \\
\hline $\mathrm{HT}_{84}$-CS-DCA 3.2 & 0.060 & $235.2 \pm 1.4(0.08)$ & $23.3 \pm 3.2$ \\
\hline
\end{tabular}

${ }^{\mathrm{a}} \mathrm{HT}_{42}$-CS-DCA 3.2 shows the DS of GTMAC is 42 , DS of DCA is 3.2, respectively. ${ }^{\mathrm{b}}$ Values in parentheses display the polydispersity index (PDI).

To avoid being recognized, caught, and destroyed by the reticuloendothelial system, it is necessary to control the particles size as small as possible to obtain long circulation [24]. The size and zeta potential of HT-CS-DCA nanoparticles ranged from 180 to $240 \mathrm{~nm}$ and 14-24 mV with the change in DS of DCA from 2.3 to 4.2 and DS of GTMAC from 42 to 84 (Table 1). The positive zeta potential of HT-CS-DCA nanoparticles may be beneficial for their high cellular uptake efficiency. With increasing DS of DCA to the same extent, the size and zeta potential increased possibly due to the higher self-aggregation capability between inter- and intra-amphiphilic chitosan molecules with higher hydrophobic interaction. Additionally, the increase in positive charge also drove inter- and intra-chain repulsion of chitosan molecules, leading to larger particles.

\subsection{Release of DOX from HT-CS-DCA Nanoparticles In Vitro}

The above CAC test displayed that poor soluble or hydrophobic drugs similar to hydrophobic pyrene can be encapsulated into HT-CS-DCA nanoparticles. In this study, DOX with poor solubility was loaded into $\mathrm{HT}_{42}$-CS-DCA nanoparticles by dialysis of polymer/DOX in DMSO/water solution against water. When the DS of DCA increased from 2.3 to 4.2 , the drug loading (LC) increased from $4.4 \%$ to $6.1 \%$ under the condition that the theoretical drug loading content is $10 \%$. Correspondingly, the size of DOX-loaded $\mathrm{HT}_{42}$-CS-DCA nanoparticles was 30-60 nm larger than that of empty ones, while the PDI almost kept monodisperse in PBS.

With regard to evaluating drug delivery systems, the in vitro release behavior is usually determined, which can provide useful guidance for the in vivo pharmacokinetics of drugs. Furthermore, the ideal drug delivery system for cancer therapy could hold the drug during circulation but release the drug in a target. The in vitro release behavior was evaluated at $37^{\circ} \mathrm{C}$ in PBS (pH 7.4). As shown in Figure 4, the accumulative amount of DOX from $\mathrm{HT}_{42}$-CS-DCA nanoparticles was only $5 \%$ in the first $2 \mathrm{~h}$ meaning no obvious burst release. Then, the accumulative amount of DOX quickly and steadily increased in $24 \mathrm{~h}$, followed by a slow and flat increase in the next $72 \mathrm{~h}$. Meanwhile, both the release speed and the accumulative amount of DOX decreased with the increase in DS of DCA in the whole release process. For instance, the accumulative amount of DOX from $\mathrm{HT}_{42}-\mathrm{CS}-\mathrm{DCA}_{2.3}$ nanoparticles was around $64 \%$, while that from $\mathrm{HT}_{42}-\mathrm{CS}_{-}-\mathrm{DCA}_{4.2}$ nanoparticles was only $47 \%$ at $96 \mathrm{~h}$. It can be ascribed to the higher grafting of hydrophobic DCA, which hindered the release of DOX and suggested that the higher substitution of the hydrophobic moiety is beneficial for the sustained release of poor soluble or hydrophobic drugs. 


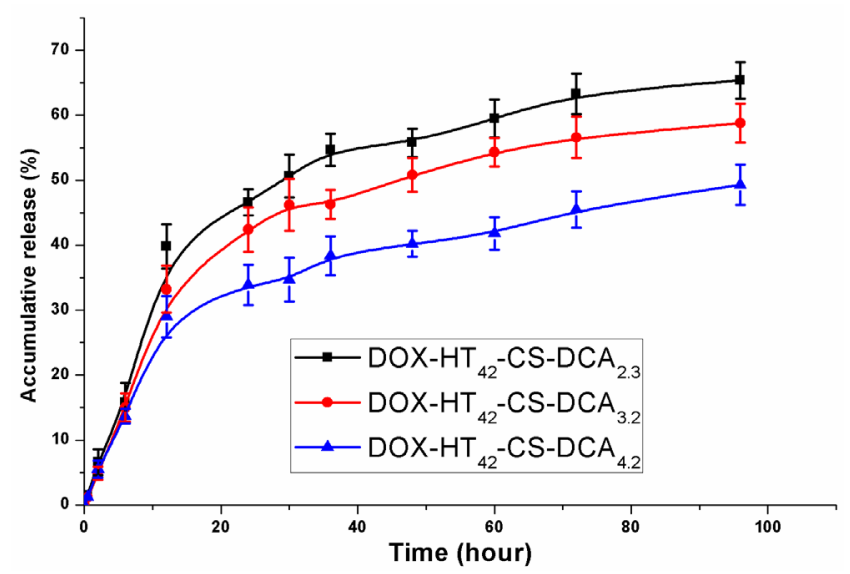

Figure 4. Release profile of DOX from $\mathrm{HT}_{42}$-CS-DCAs nanoparticles in $0.02 \mathrm{M}$ PBS (pH 7.4) at $37{ }^{\circ} \mathrm{C}$. Data represent mean \pm s.d. $(n=3)$.

\subsection{Confocal Laser Scanning Microscopic (CLSM) Observations on Cellular Uptake}

The cellular uptake of DOX- $\mathrm{HT}_{42}$-CS-DCA nanoparticles was detected by CLSM. After incubating MCF-7 cells (Shanghai Institute of Biochemistry and Cell Biology, Chinese Academy of Sciences) with DOX- $\mathrm{HT}_{42}-\mathrm{CS}-\mathrm{DCA}_{3.2}$ and free $\mathrm{DOX} \bullet \mathrm{HCl}$ for 2 and $5 \mathrm{~h}$, the medium was discarded, and the cells in the wells were washed with PBS. As shown in Figure 5, a time-dependent fluorescent intensity was observed within $5 \mathrm{~h}$ (Figure 5a,b). Interestingly, after $2 \mathrm{~h}$ incubation with free $\mathrm{DOX} \bullet \mathrm{HCl}$, a certain degree of fluorescence intensity was observed (Figure 5a); however, no fluorescence intensity was detected while cells were incubated with $\mathrm{DOX}-\mathrm{HT}_{42}-\mathrm{CS}-\mathrm{DCA}_{3.2}$ nanoparticles (Figure $5 \mathrm{c}$ ). The results may be ascribed to the self-quenching effect of DOX in nanoparticles-even nanoparticles entered cells, and fluorescence only could be detected when DOX is released $[25,26]$. There was an increase in fluorescence intensity observed after cell incubation with DOX $-\mathrm{HT}_{42}$

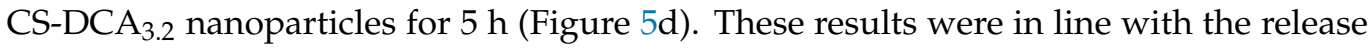
profile of DOX from DOX $-\mathrm{HT}_{42}-\mathrm{CS}-\mathrm{DCA}_{3.2}$ nanoparticles in vitro because about $15 \%$ of DOX was released at this time. Notably, Figure $5 b$ indicates that free DOX $\bullet \mathrm{HCl}$ distributed in the cell nucleus, while the fluorescence of DOX-HT ${ }_{42}-\mathrm{CS}-\mathrm{DCA}_{3.2}$ nanoparticles was mainly dotted in the cytoplasm and partly entered in the cell nucleus (Figure 5d). It was shown that cationic DOX- $\mathrm{HT}_{42}-\mathrm{CS}-\mathrm{DCA}_{3.2}$ nanoparticles were taken up by cells through endocytic vesicles, then escaped from the endosome and/or the lysosome for entering the cytoplasm, accompanied by the cytosolic release of DOX. Many unprotonated $1^{\circ}-$, $2^{\circ}$-amines in chitosan derivatives will show different $\mathrm{pKa}$ values with the crowded amines and will provide a proton buffering effect in a $\mathrm{pH}$ range [27]. The $\mathrm{pH}$ of the endosomes is lower, the proton buffering capacity of chitosan derivatives correlate with $4^{\circ}$-amines from GTMAC, and is in favor of influx of protons, chloride ions, and water into the endosomes, which give rise to swelling and burst of endosome due to the increase in osmotic pressure.

\subsection{Cellular Viability Study In Vitro}

The MCF-7 cell line was employed to investigate the anticancer efficacy of DOX- $\mathrm{HT}_{42}-$

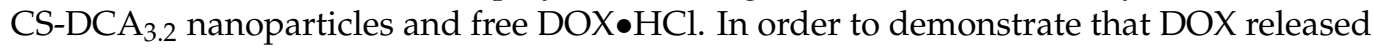
from chitosan derivatives nanoparticles, instead of $\mathrm{HT}_{42}$-CS-DCA itself, kill the cells, $\mathrm{H}_{42^{-}}$ CS-DCA nanoparticles without drugs were added in cells as a control group. The results revealed that these nanoparticles have low cytotoxicity because more than $80 \%$ of cells were still viable even under the concentration of the $\mathrm{H}_{42}$-CS-DCA nanoparticles as high as $1000 \mu \mathrm{g} / \mathrm{mL}$ (Figure 6a). However, as the concentration of DOX in $\mathrm{HT}_{42}$-CS-DCA nanoparticles changed from $1 \mu \mathrm{g} / \mathrm{mL}$ to $50 \mu \mathrm{g} / \mathrm{mL}$, the cell viability of MCF-7 reduced from almost $100 \%$ to less than $15 \%$ after incubation for $48 \mathrm{~h}$. The free drug dissolved in PBS showed similar anticancer efficacy to $\mathrm{DOX}-\mathrm{HT}_{42}-\mathrm{CS}_{-} \mathrm{DCA}_{3.2}$ nanoparticles. As shown in Figures 4 and $6 \mathrm{~b}$, DOX released slowly from $\mathrm{HT}_{42}$-CS-DCA nanoparticles before entering 
the nucleus to take drugs into effect through interaction with DNA; therefore, the anticancer efficacy of DOX- $\mathrm{HT}_{42}$-CS-DCA lagged a little behind free $\mathrm{DOX} \bullet \mathrm{HCl}$ within $48 \mathrm{~h}$. We observed there was almost no difference in the anticancer efficacy of DOX- $\mathrm{HT}_{42}$-CS-DCA nanoparticles with varied DS of DCA, because the anticancer efficacy may be influenced by several factors including particles size, zeta potential, the interaction strength between DOX and DCA, and the site of the drug inside the micelle core.

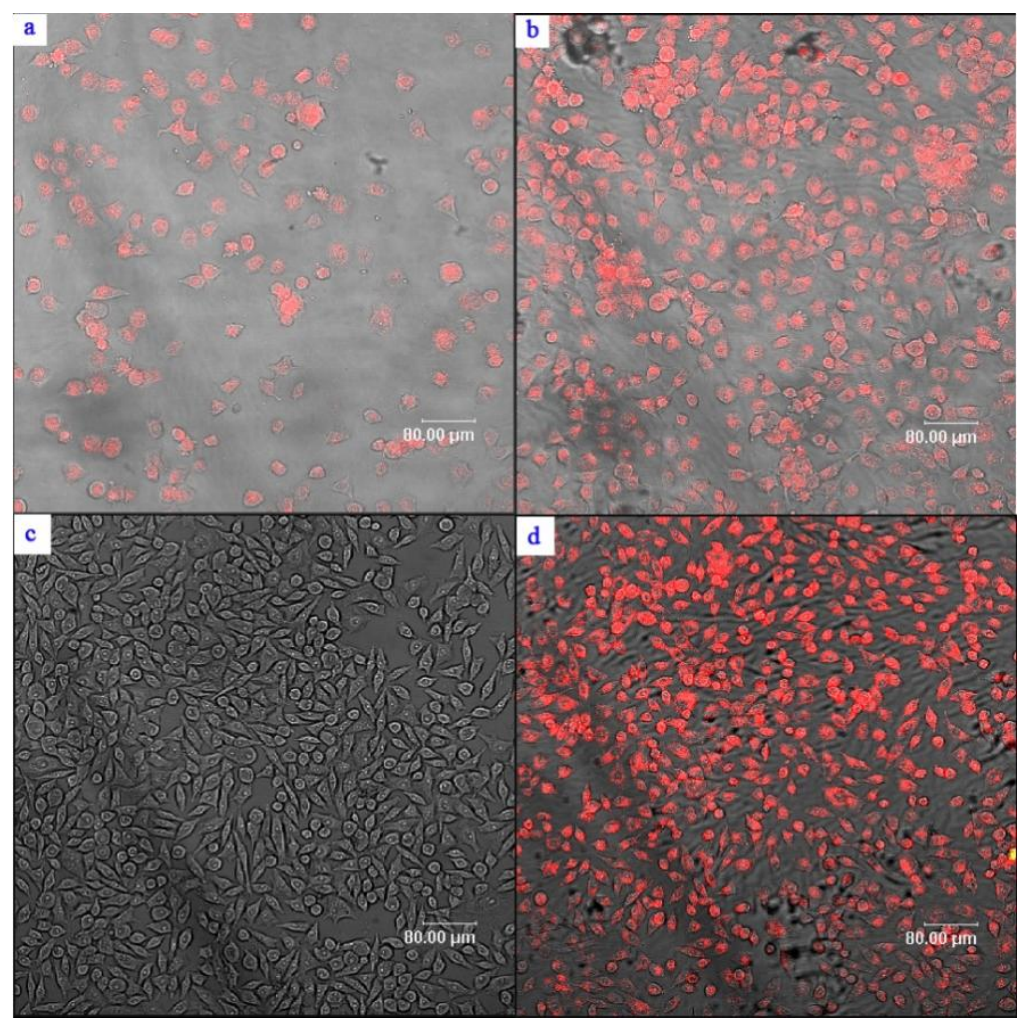

Figure 5. CLSM images of MCF-7 cells cultured with DOX and DOX- $\mathrm{HT}_{42}-\mathrm{CS}-\mathrm{DCA}_{3.2}$ nanoparticles ( $5 \mu \mathrm{g} / \mathrm{mL}$ of DOX): (a) free DOX after $2 \mathrm{~h}$ incubation; (b) free DOX after $5 \mathrm{~h}$ incubation; (c) $\mathrm{DOX}-\mathrm{HT}_{42}{ }^{-}$ CS-DCA 3.2 nanoparticles after $2 \mathrm{~h}$ incubation; (d) DOX- $\mathrm{HT}_{42}-\mathrm{CS}-\mathrm{DCA}_{3.2}$ after $5 \mathrm{~h}$ incubation.

a

HT42-CS-DCA4.2

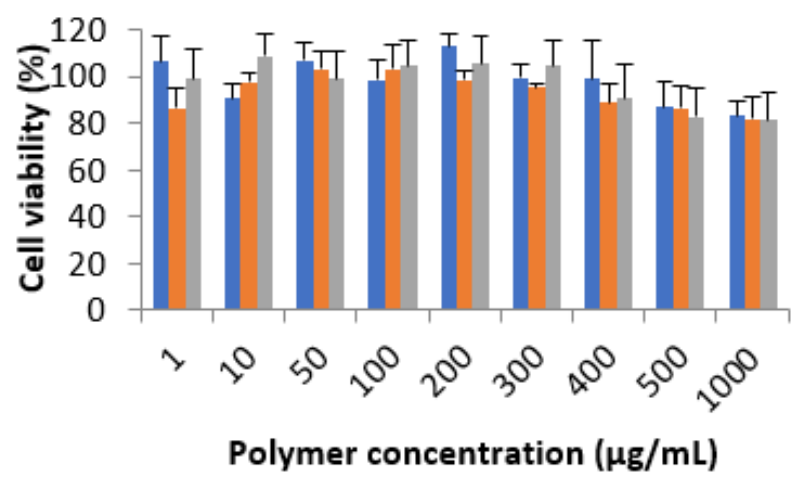

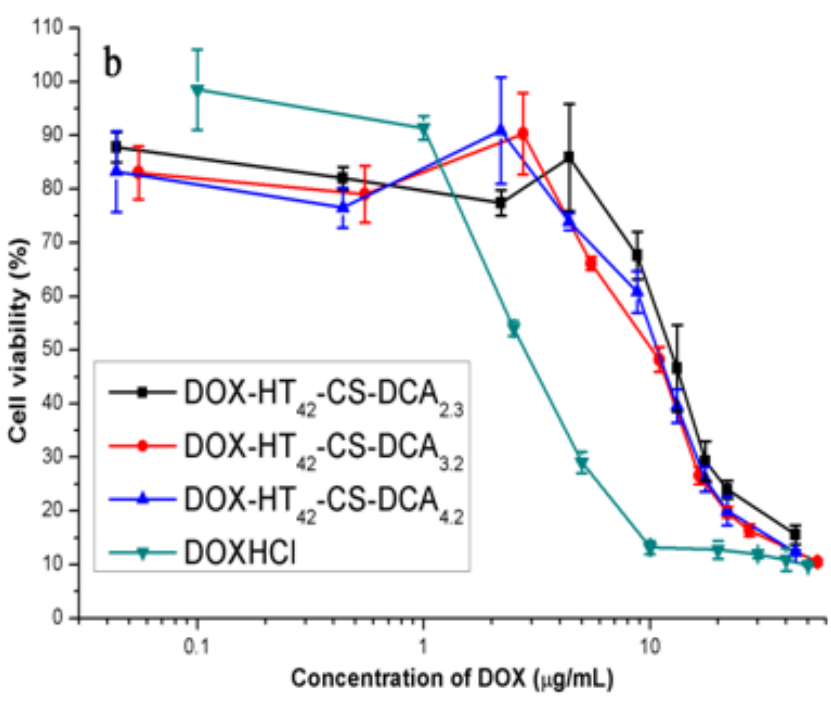

Concentration of DOX ( $\mu \mathrm{g} / \mathrm{mL})$

Figure 6. Cytoactivity test of MCF-7 cells cultured with $\mathrm{HT}_{42}$-CS-DCA nanoparticles for $48 \mathrm{~h}$ (a); the results represent the average value $\pm \mathrm{SD}(n=6)$. Cytoactivity test of MCF-7 cells cultured with DOX-HT 42 -CS-DCA nanoparticles and $\mathrm{DOX} \bullet \mathrm{HCl}$ for $48 \mathrm{~h}(\mathbf{b})$; the results represent the average value $\pm \mathrm{SD}(n=6)$. 


\section{Conclusions}

We successfully developed a novel cationic soluble amphiphilic chitosan derivatives HT-CS-DCA to fabricate nanocarriers for the delivery of anticancer drugs, doxorubicin. Based on self-assembly, the cationic amphiphilic HT-CS-DCA nanoparticles were spherical in shape, with an average size around $200 \mathrm{~nm}$ and zeta potential ranging from 14 to $24 \mathrm{mV}$ in PBS (pH 7.4). The CAC values of HT-CS-DCA nanoparticles were in the range from $0.079 \mathrm{mg} / \mathrm{mL}$ to $0.023 \mathrm{mg} / \mathrm{mL}$ according to the variation of DS values of DCA and GTMAC. DOX encapsulated in HT-CS-DCA nanoparticles showed no obvious burst release and kept a slow, sustained release, with adjustable release speed by changing DS of DCA. Fluorescence imaging experiments indicated DOX encapsulated in HT-CSDCA nanoparticles could be easily delivered into tumor cells and then released from nanoparticles to inhibit tumor cell growth. Therefore, HT-CS-DCA nanoparticles have a high potential of delivering DOX and other kinds of poorly soluble or hydrophobic drugs.

Author Contributions: Conceptualization, funding acquisition, and writing-review and editing, X.L.; investigation, data analyses and writing-original draft preparation; H.Z. conceptualization, visualization and analyses, and results discussion, W.Y.; methodology, results discussion, and writingreview \& editing, X.X. and R.K.; Supervision, resources, and results discussion, X.M. All authors have read and agreed to the published version of the manuscript.

Funding: This research was funded by the Scientific Research Project of Universities of the Education Department of Liaoning Province (LJKZ1183), the BaiQianWan Talents Program of Liaoning Province (No. 2017-6), and the National Natural Science Foundation of China (No. 20876018). NMI received financial support from the State Ministry of Baden-Württemberg for Economic Affairs, Labour, and Housing Construction.

Conflicts of Interest: The authors declare no conflict of interest.

$\begin{array}{ll}\text { Abbreviations } \\ \text { CS } & \text { Chitosan } \\ \text { CLSM } & \text { Confocal laser scanning microscopy } \\ \text { CAC } & \text { Critical aggregation concentration } \\ \text { DCA } & \text { Deoxycholic acid } \\ \text { DOX } & \text { Doxorubicin } \\ \text { EE } & \text { Encapsulation efficiency } \\ \text { EDC•HCl } & \text { 1-ethyl-3-(3-dimethylaminopropylCarbodiimide hydrochloride } \\ \text { GTMAC } & \text { Glycidyltrimethylammounium chloride } \\ \text { HT-CS-DCA } & \text { N-(2-hydroxy)propyl-3-trimethylammnonium-chitosan-deoxycholic acid } \\ \text { LC } & \text { Loading content } \\ \text { MCF-7 } & \text { Human breast cancer cells } \\ \text { MTT } & \text { Methyl tetrazolium } \\ \text { MWCO } & \text { Molecular weight cut-off } \\ \text { NHS } & \text { N-hydroxysuccimide } \\ \text { PDI } & \text { Polydispersity index }\end{array}$

\section{References}

1. Gaucher, G.; Marchessault, R.H.; Leroux, J.C. Polyester-based micelles and nanoparticles for the parenteral delivery of taxanes. J. Control Release 2010, 143, 2-12. [CrossRef]

2. Hwang, D.; Ramseya, J.D.; Kabanov, A.V. Polymeric micelles for the delivery of poorly soluble drugs: From nanoformulation to clinical approval. Adv. Drug Deliv. Rev. 2020, 156, 80-118. [CrossRef] [PubMed]

3. Marinheiro, D.; Ferreira, B.J.M.L.; Oskoei, P.; Oliveira, H.; Daniel-da-Silva, A.L. Encapsulation and enhanced release of resveratrol from mesoporous silica nanoparticles for melanoma therapy. Materials 2021, 14, 1382. [CrossRef] [PubMed]

4. Ding, J.X.; Chen, J.J.; Gao, L.Q.; Jiang, Z.Y.; Zhang, Y.; Li, M.Q.; Xiao, Q.C.; Lee, S.S.; Chen, X.S. Engineered nanomedicines with enhanced tumor penetration. Nanotoday 2019, 29, 100800. [CrossRef]

5. Sun, H.L.; Dong, Y.Y.; Feijen, J.; Zhong, Z.Y. Peptide-decorated polymeric nanomedicines for precision cancer therapy. J. Control Release 2018, 290, 11-27. [CrossRef] [PubMed] 
6. Suzuki, H.; Bae, Y.H. Evaluation of drug penetration with cationic micelles and their penetration mechanism using an in vitro tumor model. Biomaterials 2016, 98, 120-130. [CrossRef] [PubMed]

7. Braunová, A.; Chytil, P.; Laga, R.; Šírová, M.; Machová, D.; Parnica, J.; Říhová, B.; Janoušková, O.; Etrych, T. Polymer nanomedicines based on micelle-forming amphiphilic or water-soluble polymer-doxorubicin conjugates: Comparative study of in vitro and in vivo properties related to the polymer carrier structure, composition, and hydrodynamic properties. J. Control Release 2020, 321, 718-733. [CrossRef]

8. Bobde, Y.; Patel, T.; Paul, M.; Biswas, S.; Ghosh, B. PEGylated N-(2 hydroxypropyl) methacrylamide polymeric micelles as nanocarriers for the delivery of doxorubicin in breast cancer. Colloids Surf. B Biointerfaces 2021, 204, 111833. [CrossRef]

9. Pang, Y.; Zhu, Q.; Liu, J.Y.; Wu, J.L.; Wang, R.B.; Chen, S.Y.; Zhu, X.Y.; Yan, D.Y.; Huang, W.; Zhu, B.S. Design and synthesis of cationic drug carriers based on hyperbranched poly(amine-ester)s. Biomacromolecules 2010, 11, 575-582. [CrossRef] [PubMed]

10. Kamra, M.; Moitra, P.; Ponnalagu, D.; Karande, A.A.; Bhattacharya, S. New water-soluble oxyamino chitosans as biocompatible vectors for efficacious anticancer therapy via co-delivery of gene and drug. ACS Appl. Mater. Interfaces 2019, 11, 37442-37460. [CrossRef]

11. Li, Y.; Thambi, T.; Lee, D.S. Co-delivery of drugs and genes using polymeric nanoparticles for synergistic cancer therapeutic effects. Adv. Healthc. Mater. 2018, 7, 1700886. [CrossRef]

12. Wang, Y.; van Steenbergen, M.J.; Beztsinna, N.; Shi, Y.; Lammers, T.; van Nostrum, C.F.; Hennink, W.E. Biotin-decorated all-HPMA polymeric micelles for paclitaxel delivery. J. Control Release 2020, 328, 970-984. [CrossRef] [PubMed]

13. Liu, X.; Feng, Z.J.; Wang, C.R.; Su, Q.; Song, H.J.; Zhang, C.N.; Huang, P.S.; Liang, X.J.; Dong, A.J.; Kong, D.L.; et al. Co-localized delivery of nanomedicine and nanovaccine augments the postoperative cancer immunotherapy by amplifying T-cell responses. Biomaterials 2020, 230, 119649. [CrossRef] [PubMed]

14. Song, Y.D.; Wu, Y.H.; Xu, L.; Jiang, T.; Tang, C.; Yin, C.H. Caveolae-mediated endocytosis drives robust siRNA delivery of polymeric nanoparticles to macrophages. ACS Nano 2021, 15, 8267-8282. [CrossRef]

15. Ryu, J.H.; Yoon, H.Y.; Sun, I.; Kwon, I.C.; Kim, K. Tumor-targeting glycol chitosan nanoparticles for cancer heterogeneity. Adv. Mater. 2020, 32, 2002197. [CrossRef] [PubMed]

16. Zhao, Z.M.; He, M.; Yin, L.C.; Bao, J.M.; Shi, L.L.; Wang, B.Q.; Tang, C.; Yin, C.H. Biodegradable nanoparticles based on linoleic acid and poly(beta-malic acid) double grafted chitosan derivatives as carriers of anticancer drugs. Biomacromolecules 2009, 10, 565-572. [CrossRef] [PubMed]

17. Zhou, H.F.; Yu, W.T.; Guo, X.; Liu, X.D.; Li, N.; Zhang, Y.; Ma, X.J. Synthesis and characterization of amphiphilic glycidolchitosan-deoxycholic acid nanoparticles as drug carrier for doxorubicin. Biomacromolecules 2010, 11, 3480-3486. [CrossRef] [PubMed]

18. Zhang, D.M.; Song, Y.Z.; Wang, Y.; Liu, X.D.; Yu, W.T.; Ma, X.J. Insight of in vitro siRNA release from chitosan nanoparticles under enzymolysis with FRET analysis. J. Pharm. Sci. 2016, 105, 301-307. [CrossRef]

19. Lu, B.; Wang, C.F.; Wu, D.Q.; Li, C.; Zhang, X.Z.; Zhuo, R.X. Chitosan based oligoamine polymers: Synthesis, characterization, and gene delivery. J. Control Release 2009, 137, 54-62. [CrossRef]

20. Almeida, A.; Araújo, M.; Novoa-Carballal, R.; Andrade, F.; Gonçalves, H.; Reis, R.L.; Lúcio, M.; Schwartz, S., Jr.; Sarmento, B. Novel amphiphilic chitosan micelles as carriers for hydrophobic anticancer drugs. Mater. Sci. Eng. C 2020, 112, 110920. [CrossRef]

21. Mu, Y.Z.; Fu, Y.M.; Li, J.; Yu, X.P.; Li, Y.; Wang, Y.N.; Wu, X.J.; Zhang, K.C.; Kong, M.; Feng, C.; et al. Multifunctional quercetin conjugated chitosan nano-micelles with P-gp inhibition and permeation enhancement of anticancer drug. Carbohyd. Polym. 2019, 203, 10-18. [CrossRef] [PubMed]

22. Liu, X.D.; Howard, K.A.; Dong, M.D.; Andersen, M.Ø.; Rahbek, U.L.; Johnsen, M.G.; Hansen, O.C.; Besenbacher, F.; Kjems, J. The influence of polymeric properties on chitosan/siRNA nanoparticle formulation and gene silencing. Biomaterials 2007, 28, 1280-1288. [CrossRef] [PubMed]

23. Zhou, H.F.; Liu, X.D.; Zhang, Y.; Ma, X.J. Preparation and characterization of nanoaggregates self-assembled by lithocholic acid and N-trimethyl modified chitosan derivatives. J. Nanosci. Nanotechnol. 2010, 10, 2304-2313. [CrossRef] [PubMed]

24. Seow, W.Y.; Xue, J.M.; Yang, Y.Y. Targeted and intracellular delivery of paclitaxel using multi-functional polymeric micelles. Biomaterials 2007, 28, 1730-1740. [CrossRef]

25. Bae, Y.; Fukushima, S.; Harada, A.; Kataoka, K. Design of environment-sensitive supramolecular assemblies for intracellular drug delivery: Polymeric micelles that are responsive to intracellular pH change. Angew. Chem. Int. Ed. 2003, 42, 4640-4643. [CrossRef]

26. Li, Y.L.; Zhu, L.; Liu, Z.Z.; Cheng, R.; Meng, F.H.; Cui, J.H.; Ji, S.J.; Zhong, Z.Y. Reversibly stabilized multifunctional dextran nanoparticles efficiently deliver doxorubicin into the nuclei of cancer cells. Angew. Chem. Int. Ed. 2009, 48, 9914-9918. [CrossRef]

27. Tseng, Y.C.; Mozumdar, S.; Huang, L. Lipid-based systemic delivery of siRNA. Adv. Drug Deliv. Rev. 2009, 61, 721-731. [CrossRef] [PubMed] 